\title{
Estimation of Anisotropy of Mechanical Properties in Mg Alloys by Means of Compressive Creep Tests
}

\author{
F. Dobeš, ${ }^{1, a}$ P. Pérez,${ }^{2, b}$ K. Milička, ${ }^{1, c}$ G. Garcés, ${ }^{2, d}$ and P. Adeva ${ }^{2, e}$ \\ ${ }^{1}$ Institute of Physics of Materials, Academy of Sciences of the Czech Republic, Brno, Czech \\ Republic \\ ${ }^{2}$ National Center of Metallurgical Investigations, Madrid, Spain \\ a dobes@ipm.cz, b zubiaur@cenim.csic.es, ${ }^{\text {c }}$ milicka@ipm.cz, ${ }^{\mathrm{d}}$ ggarces@cenim.csic.es, \\ 'adeva@cenim.csic.es
}

A detailed knowledge of dependence of mechanical properties on orientation in materials prepared by directional processes may present an important factor influencing the design of construction parts. Toward this end, the compressive creep testing of short specimens may be useful. Three different magnesium-based materials were subjected to this testing: (i) pure magnesium, (ii) magnesium matrix composite reinforced with 10 vol.\% of titanium, and (iii) magnesium alloy WE54. All three materials were prepared through a powder metallurgical route with final hot extrusion. The specimens for creep tests were cut in such a way that their longitudinal axis (i.e., the direction of compressive creep stress) and the axis of extruded bar contained a predestined angle. Two extreme cases can be observed: In pure $\mathrm{Mg}$ and in $\mathrm{Mg}-\mathrm{Ti}$ composite, the dependence of the creep rate is very sensitive to the orientation especially at small inclinations from extrusion axis. The greatest creep resistance is observed in specimens with stress axis parallel to the extrusion axis, the lowest at declinations from 45 to $90^{\circ}$. On the other hand, in WE54 no orientation dependence was observed. Possible explanations of the behaviour based on microstructural observations are discussed.

Keywords: magnesium, creep, composite, texture.

Introduction. Microstructure of many materials - either intentionally or owing to production history - is not isotropic. Consequently, mechanical properties are not isotropic, too. A detailed knowledge of dependence of these properties on orientation within material may be important for an exact design of construction parts. An investigation of orientation dependence may also contribute to identification of mechanisms that control the respective property. The anisotropy of mechanical properties is important in hexagonal metals and alloys, especially in light-weighted magnesium alloys and a great attention has been recently devoted to its study [1-6]. We present the results of orientation dependence of creep properties of magnesium-based alloys prepared by powder metallurgical processing.

Experimental. Commercially pure magnesium powder with a particle size less than $45 \mu \mathrm{m}$ and grain sizes ranging between 1 and $8 \mu \mathrm{m}$, was cold-pressed at $310 \mathrm{MPa}$ pressure level, leading to a densification of around $95 \%$. The compacts were hot-extruded into rods at $673 \mathrm{~K}$ using an extrusion ratio of $18: 1$.

A magnesium matrix composite reinforced with 10 vol. $\%$ of titanium particles was prepared from the same magnesium powder as the previous material and from the titanium powder of particle size less than $25 \mu \mathrm{m}$. The powders were mixed for $3 \mathrm{~h}$ at 100 rpm in a planetary mill. The next technology steps were identical with those for the pure magnesium material: cold-pressing at $310 \mathrm{MPa}$ and hot-extrusion into rods at $673 \mathrm{~K}$ using an extrusion ratio of $18: 1$.

The third investigated material was the magnesium-based alloy WE54 alloy. The alloy contained 5 wt. $\%$ of $\mathrm{Y}, 2$ wt. $\%$ of $\mathrm{Nd}$, and 2 wt. $\%$ of rare earth elements. The powder prepared by rapid solidification had size less than $100 \mu \mathrm{m}$. The powder was 
cold-pressed by slowly increasing pressure up to $340 \mathrm{MPa}$ in a special die designed for this purpose. The resulting compacts of $40 \mathrm{~mm}$ in diameter were extruded at $673 \mathrm{~K}$ employing an extrusion ratio of $20: 1$.

Results of the subsequent characterization of materials by optical microscopy, scanning electron microscopy, X-ray diffraction and tensile tests are given elsewhere [7-9].

Cylindrical specimens of diameter $5 \mathrm{~mm}$ and height $9 \mathrm{~mm}$ were prepared by spark-cutting from the extruded bars. The specimens were cut in such a way that their longitudinal axis (i.e., the direction of compressive creep stress) and the axis of extruded bar contained a predestined angle from 0 to $90^{\circ}$. Constant load compressive creep tests of the alloy were performed at temperatures from 523 to $623 \mathrm{~K}$. A stepwise loading was used: in each step, the load was changed to a new value after stationary creep rate had been established. The terminal values of the true stress and the true strain rate were evaluated for the respective step. Protective atmosphere of dried and purified argon was used. During the test, temperature was kept constant within $\pm 1 \mathrm{~K}$. Creep curves were PC recorded by means of special software. The sensitivity of elongation measurements was better than $10^{-5}$.

Results. Examples of experimental dependences of the creep rate $\dot{\varepsilon}$ on the applied stress $\sigma$ for different orientations of specimens are given in Figs. 1-3. Two basic patterns of behavior can be observed: In pure $\mathrm{Mg}$ and in $\mathrm{Mg}-\mathrm{Ti}$ composite, the dependence of the creep rate is very sensitive to the orientation especially at small inclinations from extrusion axis. The highest creep resistance is observed in specimens with stress axis parallel to the extrusion axis, while the lowest resistance is at declinations from 45 to $90^{\circ}$. A more exact determination of orientation with the lowest creep resistance is complicated by the scatter of experimental data. On the other hand, in WE54 no orientation dependence is observed. Another feature that distinguishes two groups is the dependence of creep rate on the applied stress. The dependences can be formally described by the power function

$$
\dot{\varepsilon}=A \sigma^{n},
$$

where $A$ is a temperature dependent factor and $n$ is exponent. The values of exponent $n$ are about 19 in pure $\mathrm{Mg}$ and from 20 up to $32 \mathrm{in} \mathrm{Mg-Ti} \mathrm{composite.} \mathrm{Relatively} \mathrm{high} \mathrm{values}$ of $n$ are typical for creep in metallic materials strengthened by dispersion of secondary phase. In the alloy WE54, the stress exponent $n$ is about 4 for all orientation.

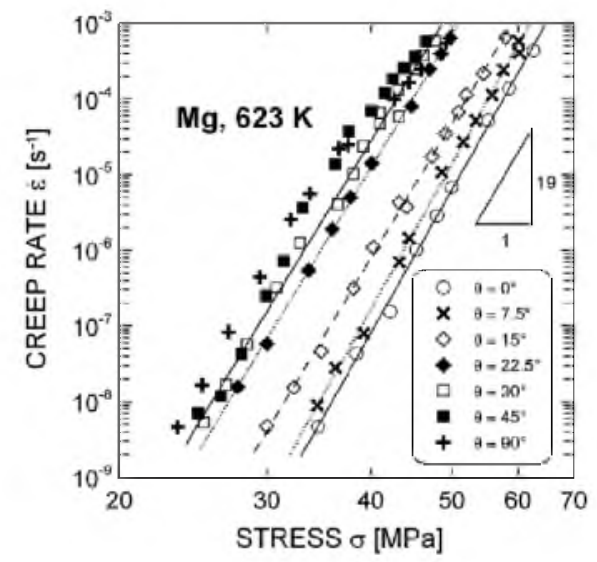

Fig. 1

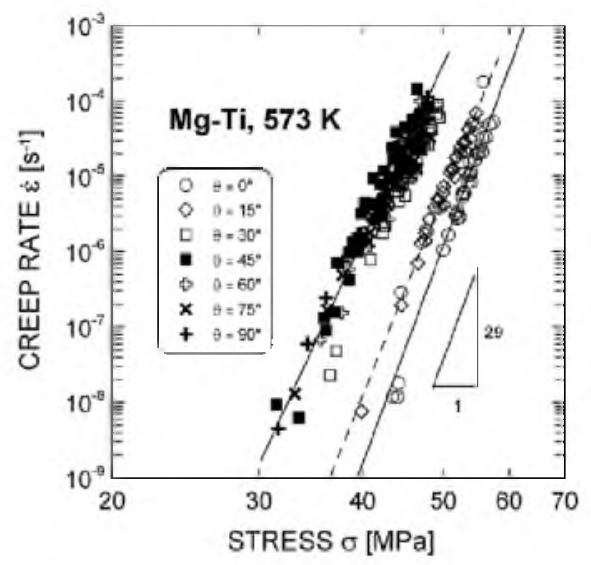

Fig. 2

Fig. 1. Dependence of creep rate on applied stress in $\mathrm{Mg}$.

Fig. 2. Dependence of creep rate on applied stress in Mg-Ti composite. 


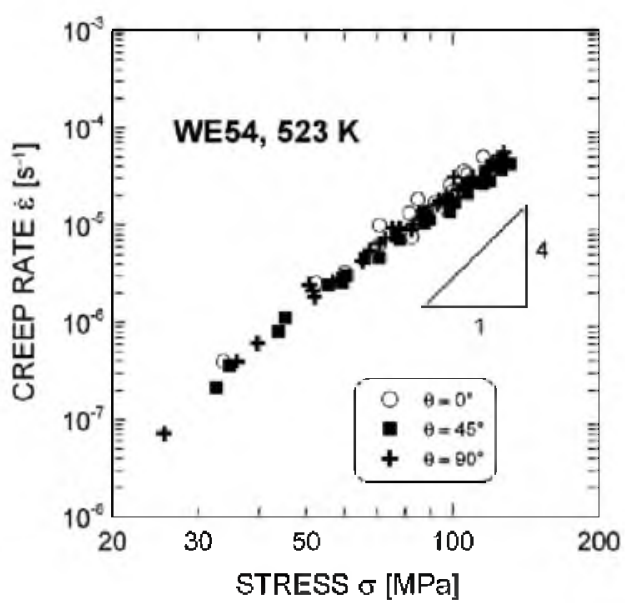

Fig. 3

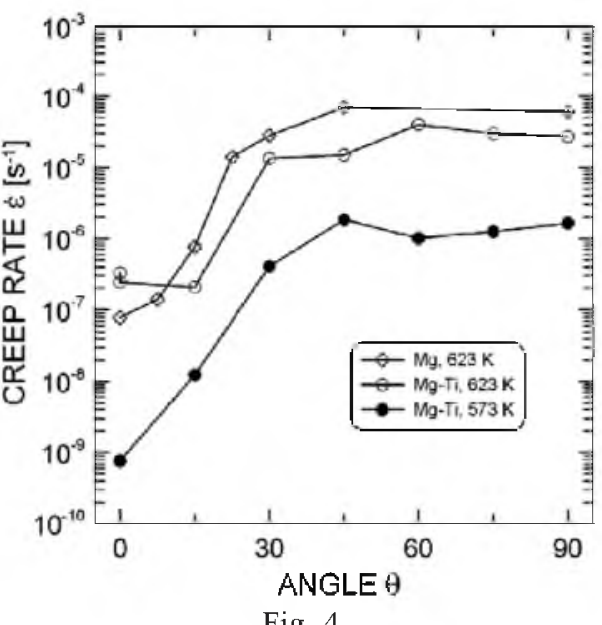

Fig. 4

Fig. 3. Dependence of creep rate on applied stress in WE54.

Fig. 4. Dependence of creep rate on orientation of samples in $\mathrm{Mg}$ and in $\mathrm{Mg}-\mathrm{Ti}$ composite.

The equation (1) was used also for an evaluation of the influence of orientation on the creep rate. The creep rates corresponding to the applied stress $40 \mathrm{MPa}$ were calculated by means of optimized values of $A$ and $n$ for all orientations. The results are given in Fig. 4.

Discussion. Microscopic observations revealed three distinct anisotropic features of the structure of alloys: (i) elongated grains, (ii) crystallographic texture and (iii) elongated oxide and titanium particles.

(i) Grains in $\mathrm{Mg}-\mathrm{Ti}$ are elongated in the extrusion direction, with an aspect ratio of about 2. It is generally accepted that the grain size and shape influences the rate of diffusional creep but not the rate of dislocation creep [10]. The diffusional creep can be excluded as possible rate-controlling mechanism due to the observed high values of stress exponent. At any rate, following the original formulation of volume diffusion controlled creep rate [11], the creep rate in specimens perpendicular to extrusion direction should be faster than in parallel direction by a factor about square root of grain aspect ratio, which is considerably less than observed experimentally.

(ii) Pure magnesium and $\mathrm{Mg}-\mathrm{Ti}$ composite exhibited a fiber texture with the basal planes parallel to the extrusion direction. For such a type of texture, the slip motion of dislocations in the extrusion direction should be the easiest. In addition to this, deformation behavior is influenced by values of the resolved shear stress on the respective slip planes and by activities of other deformation mechanism and slip systems. At room temperature, it was shown that the yield stress is the lowest for tension parallel to extrusion axis and it was ascribed to possibility of twinning. However, at elevated temperatures, twining tends to be inhibited and this fact leads to strong texture strengthening, especially if the test temperature is not high enough for the activation of non-basal slip systems.

(iii) Titanium particles in $\mathrm{Mg}-\mathrm{Ti}$ composite are very often highly deformed; they are elongated in the extrusion direction to such an extent that they can be considered as long fibres. Their existence seems to be another plausible reason for an explanation of the observed creep behavior [12]. Similar mechanism has to be taken into account also in pure-magnesium material due to its powder-metallurgical processing, since the grains elongated in the extrusion direction are decorated by oxide particles. These particles come from the fracture during the extrusion of the oxide film which covers the original magnesium powders. 
The negative effect of specimen tilt on creep resistance in WE54 can be related to a randomization of grain orientation. Since the deformation texture should not be very distinct from other magnesium alloys, it is thus probable that the resulting texture is influenced by recrystallization. This effect is associated with nucleation of recrystallization stimulated by second-phase particles $[13,14]$ and can have a positive importance for ensuing technological processes.

Acknowledgments. The financial support of the Grant Agency of the Czech Republic within the project 106/06/1354 is gratefully acknowledged. The paper was prepared within the joint research program of the Spanish National Research Council CSIC and the Academy of Sciences of the Czech Republic.

1. H. Somekawa and T. Mukai, Scripta Mater., 53, 541 (2005).

2. L. Helis, K. Okayasu, and H. Fukutomi, Mater. Sci. Eng. A, 430, 98 (2006).

3. J. A. del Valle and O. A. Ruano, Acta Mater., 55, 455 (2007).

4. D. K. Xu, L. Liu, Y. B. Xu, and E. H. Han, Mater. Sci. Eng. A, 443, 248 (2007).

5. G. Garcés, M. Rodríguez, P. Pérez, and P. Adeva, Composit. Sci. Technol, 67, 632 (2007).

6. J. Bohlen, M. R. Nurnberg, J. W. Senn, et al., Acta Mater., 55, 2101 (2007).

7. P. Pérez, G. Garcés, and P. Adeva, J. Mater. Sci. (in print).

8. P. Pérez, G. Garcés, and P. Adeva, Composit. Sci. Technol., 64, 145 (2004).

9. G. Garcés, M. Maeso, P. Pérez, and P. Adeva, Mater. Sci. Eng. A (in print).

10. J. P. Poirier, Plasticité à Haute Température des Solides Cristallins, Editions Eyrolles, Paris (1976).

11. C. Herring, J. Appl. Phys., 21, 437 (1950)

12. F. Dobeš, P. Pérez, K. Milička, et al., in: K. Kainer (Ed.), Proc. of the 7th Int. Conf. on Magnesium Alloys and Their Application, WILEY-VCH, Weinheim, FRG (2007), p. 699.

13. E. A. Ball and P. B. Prangnell, Scripta Metall. Mater., 31, 111 (1994).

14. G. W. Lorimer, L. W. F. Mackenzie, F. J. Humphreys, and T. Wilks, Mater. Sci. Forum, 467-470, 477 (2004), 488-489, 99 (2005).

Received 28. 06. 2007 